\title{
Impact of Online Flow Experience on Personality Variables, Subjective Happiness and Satisfaction with Life
}

\author{
Soma Parija ${ }^{1}$, Dr. Asmita Shukla ${ }^{2}$ \\ ${ }^{1}$ (Research Scholar, ${ }^{2}$ Assistant Professor, School of Humanities, Social Sciences and Management, Indian \\ Institute of Technology Bhubaneswar, India)
}

\begin{abstract}
This empirical study aims to investigate the mediating effect of online flow experience on the relationship between personality variables (extraversion/introversion and locus of control) and positive psychology (subjective happiness and satisfaction with life). Using a questionnaire, data was collected in two phases from 221 persons from different professions. Extraversion/introversion and locus of control (IVs) and subjective happiness and satisfaction with life (DVs) were obtained in the first phase, and then the subjects were asked to browse the net for three months on a minimum of four hours per day. Then in the second phase of data collection, online flow experience (mediator) and DVs were obtained from the same subjects. Data were analysed using regression analysis techniques. The findings of the study suggest that online flow experience mediates the effects of personality variables on subjective happiness and satisfaction with life. There is also a positive significant relationship between extraversion, internal locus of control, and subjective happiness and satisfaction with life.
\end{abstract}

Keywords: Extraversion/Introversion, Locus of Control, Online Flow Experience, Satisfaction with Life, Subjective Happiness

\section{Introduction}

Internet as a technology profoundly influences our day-to-day living. It helps us in easy access to a large amount of information, speed in finding world wide events, a very attractive alternative in spending the free time, the improvement of the cognitive capacity, a stronger self confidence, a higher self esteem, decreasing the boredom and the temporarily depression, increasing the number of friends from chat services and the refuge into another world. People identify themselves on the net when they are in a state of flow. Online flow experience is the state occurring during network navigation which is characterized by a seamless sequence of responses facilitated by machine interactivity, intrinsically enjoyable, accompanied by a loss of selfconsciousness, and self reinforcing [1]. So, the behavior of individuals varies in real and virtual world. Two main personality tendencies: extraversion and introversion has been identified that play a role on life in cyberspace [2]. The extrovert is a friendly person who seeks company, desires excitement, takes risks, and acts on impulse, whereas the introvert is a quiet, reflective person who prefers his or her own company and does not enjoy large social events; he or she does not crave excitement and may be seen by some as distant and remote. The locus of control structure [3] shows a distribution on dimensions of internal-external locus of control in a way it was bound to individual perceives degree of their own responsibilities for events influence the life of virtual humans. Internet overuse causes problems like informational overload, internet based relation addiction, forgets face to face communication, the student's involvement in educational programs decreases, eye problems, headaches and back pains occur, continuous tiredness due to the lack of sleep, the lack of physical activity, not paying attention to basic needs, low communication with family and decreasing social activities [4]. Subjective happiness, defined as a mental state of well-being characterized by positive emotions ranging from contentment to intense joy [5] and satisfaction with life, which is an overall assessment of feelings and attitudes about one's life at a particular point in time ranging from negative to positive [6] is hampered by overuse of the Internet.

\subsection{Main Effects}

\section{Review Of Literature}

A study explores the relationship between extraversion and subjective happiness [7]. It was found that happiness is correlated with extraversion and enjoyment and participation in social activities. The importance of extraversion/introversion and happiness was also examined by [8]. Based on the data collected, the results show that extraversion is positively correlated and introversion is negatively correlated with subjective happiness. Another study examined to what extent personality traits: extraversion and introversion was significantly correlated with happiness [9]. Regression analysis was used to analyze the data which revealed that extraversion was a significant, direct, predictor of happiness. The relationship between happiness and locus of control were explored by [10]. Results indicated that there was a significant positive relationship between internal locus of control and subjective happiness. 
Personality dispositions such as extraversion/introversion and neuroticism can markedly influence levels of satisfaction with life and subjective well being of people. Satisfaction with life and subjective well being were positively correlated with extraversion, while introverts were found to have lower levels of life satisfaction and subjective well being [11]. Satisfaction with life, physical status, emotional health, social support and locus of control in the frail elderly was examined [12]. People with internal locus of control had a higher level of satisfaction with life than people with external locus of control.

\subsection{Mediating Effects}

The relationship between personality variables and online flow experiences was examined by [13]. An individual's action in the flow state is experienced "as a unified flowing from one moment to the next, in which he is in control of his actions, and in which there is little distinction between self and environment, between stimulus and response, or between past, present, and future" [14]. Individuals' self-consciousness disappears, sense of time becomes distorted, and the resulting state of mind is extremely gratifying when he/she is in a state of flow (Hoffman and Novak, 1996). Introverted people locate their "real me" on the internet, while extroverted people locate their "real me" through traditional social interaction [15].

A study on consumer control in online environments was conducted by [1]. Results showed that number of years on the internet, satisfaction with their internet skills and goal-directed usage of the internet was positively correlated with internal locus of control and negatively correlated with external locus of control. Whereas, web use substituting for other activities and beliefs that internet content should be regulated through filter use or the government was negatively correlated with internal locus of control and positively correlated with external locus of control. The relationship between locus of control and Internet use was found out [16]. It revealed a significant positive correlation between external locus of control and problem Internet use. There exists a positive relationship between external locus of control and Internet use [17]. The higher the tendency of one being addicted to the Internet, the shyer the person is, the less faith the person has, the firmer belief the person holds in the irresistible power of others and the higher trust the person places on chance in determining his or her own course of life.

\section{Research Gap}

According to many recent studies, personality variables play an important role on online flow experience, subjective happiness and satisfaction with life. Although past studies have proposed that extraversion/introversion and locus of control has a direct influence on subjective happiness and satisfaction with life in different context; to the best of our knowledge, no research has been carried out to examine the mediating effect of online flow experience on the relationship between extraversion/introversion and locus of control, and subjective happiness and satisfaction with life.

So a modified model based on the literature is proposed to fill the research gap. Based on the research propose, we develop following research questions for further study

- What is the relationship between personality variables and subjective happiness and satisfaction with life?

- Will online flow experience mediate the relationship of extraversion/introversion and locus of control, and subjective happiness and satisfaction with life?

This study further contributes the existing body of knowledge by examining the mediating role of online flow experience on the relationship between personality variables and positive psychology.

\section{PROPOSED CONCEPTUAL FRAMEWORK}

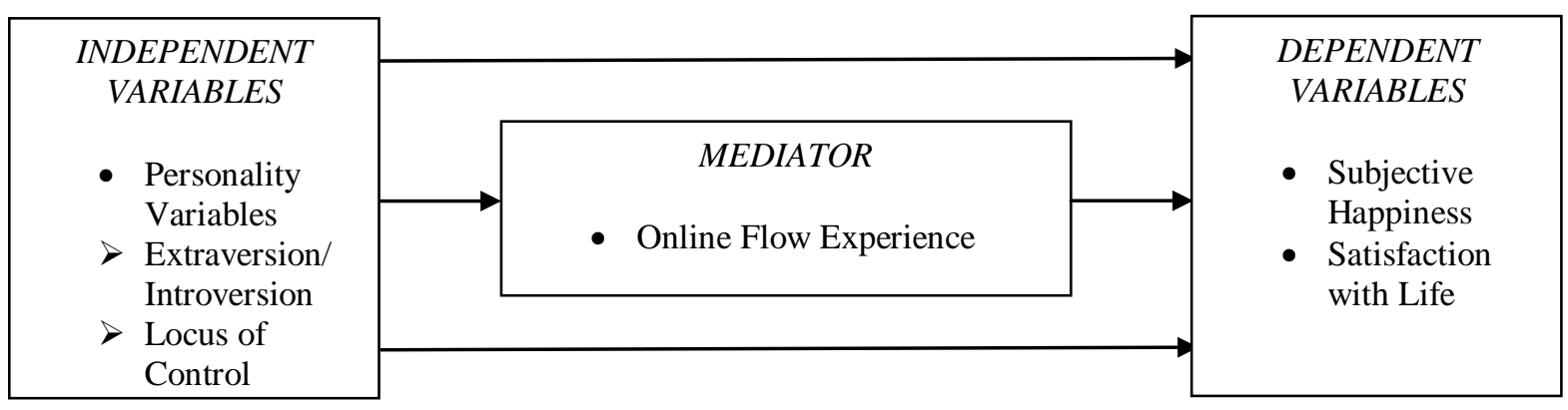




\section{Objectives}

The research objectives of this study are as follows:

A. To examine whether the effect of extraversion/introversion determine person's subjective happiness and satisfaction with life.

B. To examine whether the effect of locus of control determine person's subjective happiness and satisfaction with life.

C. To examine the role of online flow experience in the relationship between extraversion/introversion and locus of control, and subjective happiness and satisfaction with life.

\section{Hypotheses}

The following hypotheses are proposed for the present research:

$\mathrm{H}_{1.1:}$ The higher the individual is on extroversion and lower is on introversion, the higher would be his/her subjective happiness.

$\mathrm{H}_{1.2:}$ The higher the individual is on external locus of control and lower is on internal locus of control, the lower would be his/her subjective happiness.

$\mathrm{H}_{2.1}$ : The higher the individual is on extraversion and lower is on introversion, the higher would be his/her satisfaction with life.

$\mathrm{H}_{2.2:}$ The higher the individual is on external locus of control and lower is on internal locus of control, the lower would be his/her satisfaction with life.

$\mathrm{H}_{3.1:}$ The effect of extraversion/introversion on subjective happiness will be mediated by online flow experience.

$\mathrm{H}_{3.2:}$ The effect of locus of control on subjective happiness will be mediated by online flow experience.

$\mathrm{H}_{3.3:}$ The effect of extraversion/introversion on satisfaction with life will be mediated by online flow experience.

$\mathrm{H}_{3.4}$ The effect of locus of control on satisfaction with life will be mediated by online flow experience.

\section{Methodology}

The methodology which was used for carrying out the research as follows

\subsection{Sample and Procedure}

Sample research included 221 subjects from different professions. There was a guarantee of confidentiality that the identity of the subjects would be anonymous in the completion of the questionnaire. There were two phases of data collection. In the first phase of the research, the data were collected using a structured questionnaire which contains all the independent variables (extraversion/introversion and locus of control) and dependent variables (subjective happiness and satisfaction with life). Then network navigation was imposed on participants for a minimum of four hours a day for a period of three months. During that time, they were asked to browse their favourite websites and in doing so they would be provided some incentives. Then after the completion of three months, the second phase of research was carried out. The data were collected from the same subjects on online flow experience and all the dependent variables using a structured questionnaire that contains all the relevant factors.

\subsection{Measures}

The items used to measure the constructs in the study are to taken from standardized scales. Measurements of some of the constructs were taken from standardized scales and some were from the scales adopted from previous studies.

The instruments used in this research are as follows:

\subsubsection{Extraversion/Introversion}

The measure of extraversion-introversion, Eysenck Personality Questionnaire Revised (EPQ-R) developed by Eysenck, H.J. \& Eysenck, Sybil, B.J. (1985) is a questionnaire to assess the personality traits of a person contains 12 items relating to the construct. The responses are measured on a binary scale of Yes (1) and No (0). Scores range from 0-12. A high score indicates extraversion while a low score indicates introversion.

\subsubsection{Locus of Control}

The Locus of Control is a 13 item forced-choice questionnaire; Rotter's Locus of Control Scale was developed by Rotter, J.B. (1966). It measures generalized expectancies for internal versus external control of reinforcement. Scores range from 0 to 13. A low score indicates an internal control while a high score indicates external control.

\subsubsection{Online Flow Experience}

The measure of online flow experience was adapted from Novak, T.P. \& Hoffman, D.L. (2003). It is a 17-item scale where the items are measured on a 6-point Likert Scale. A high score indicates higher online flow experience. 


\subsubsection{Subjective Happiness}

The measure of subjective happiness, Subjective Happiness Scale (SHS) was developed by Sonja Lyubomirsky (1997). It is a 4-item scale of global subjective happiness. The items are measured on a 6-point Likert Scale. A higher score indicates higher subjective happiness.

\subsubsection{Satisfaction with Life}

The measure of satisfaction with life, Satisfaction with Life Scale (SWLS) was developed by Diener et al., 1985 is used to assess specific to a particular domain of life. SWLS is a global measure of life satisfaction. The SWLS consists of 5-items that are completed by the individual whose life satisfaction is being measured. The items are measured on a 6-point Likert Scale ranging from 'very strongly disagree' (1) to 'very strongly agree' (6). A high score indicates higher life satisfaction.

\section{Results And Discussion}

To test the relationship between the independent variables and dependent variables and for the mediating effect, regression analysis is used. Data were analyzed through SPSS v.18. The key questions addressed by this research are as follows. (A) Will personality variables have an impact on subjective happiness and satisfaction with life? (B) Does online flow experience mediate the above said relationship? In this section, we examine the results of the model estimation and draw conclusions regarding the relative strength of each of these hypothesized effects.

\subsection{Main Effects}

To study the relationship between independent variable and dependent variables, regression analysis is used. $\mathrm{H}_{1.1}$ deals with the main effects of extraversion/introversion on subjective happiness and $\mathrm{H}_{1.2}$ deals with the main effects of locus of control on subjective happiness.

The regression equations to test the effect of personality variables on subjective happiness are:

$\mathrm{SH}=\beta_{0}+\beta_{1} \mathrm{EI}(1)$

$\mathrm{SH}=\beta_{0}+\beta_{1}$ LOC (2)

Where, $\beta=$ Regression Coefficient, $\mathrm{SH}=$ Subjective Happiness, EI = Extraversion/Introversion, LOC $=$ Locus of Control

Table 1. Summary of Regression Analysis to Measure the Effect of Personality Variables on Subjective Happiness

\begin{tabular}{|c|c|c|c|c|c|c|c|c|}
\hline Variable & $\mathrm{B}$ & SE (B) & $\beta$ & $\mathrm{R}^{2}$ & $\Delta \mathrm{R}^{2}$ & $\mathrm{~F}$ & $\mathrm{t}$ & Tolerance \\
\hline \multicolumn{9}{|c|}{$\mathrm{SH}=\beta_{0}+\beta_{1} \mathrm{EI}(1)$} \\
\hline EI & 961 & .024 & 961 & .924 & $.924 *$ & $1572.921 *$ & $39.660 *$ & 1.00 \\
\hline \multicolumn{9}{|c|}{$\mathrm{SH}=\beta_{0}+\beta_{1} \mathrm{LOC}(2)$} \\
\hline LOC & -.869 & .022 & -.869 & .839 & $.839^{*}$ & 1989.277* & $-44.601 *$ & 1.00 \\
\hline
\end{tabular}

Table 1 exhibits the results of regression analysis for both extraversion/introversion and locus of control. As a determinant of subjective happiness, scores on extraversion/introversion accounted for $92 \%$ of variance $\left(\mathrm{R}^{2}\right.$ Change $\left.=.924 ; \mathrm{F}=1572.921 ; \mathrm{p}<.05\right)$. Extraversion has a direct and positive effect on subjective happiness $(\beta=.961 ; \mathrm{p}<.05)$. So, the hypothesis is significant. Locus of control also have an impact on subjective happiness as the results are significant $\left(\mathrm{R}^{2}\right.$ Change $\left.=.839 ; \mathrm{F}=1989.277 ; \mathrm{p}<.05\right)$. External locus of control has a direct and negative effect on subjective happiness $(\beta=-.869 ; \mathrm{p}<.05)$. These results support the hypotheses $\mathrm{H}_{1.1}$ and $\mathrm{H}_{1.2}$.

$\mathrm{H}_{2.1}$ deals with the main effects of extraversion/introversion on satisfaction with life and $\mathrm{H}_{2.2}$ deals with the main effects of locus of control on satisfaction with life.

The regression equations to test the effect of personality variables on satisfaction with life are:

$\mathrm{SL}=\beta_{0}+\beta_{1} \mathrm{EI}(3)$

$\mathrm{SL}=\beta_{0}+\beta_{1} \mathrm{LOC}(4)$.

Where, $\beta=$ Regression Coefficient, SL $=$ Satisfaction with Life, EI = Extraversion/ Introversion, LOC $=$ Locus of Control 
Impact of Online Flow Experience on Personality Variables, Subjective Happiness and Satisfaction with

Table 2 Summary of Regression Analysis of Extraversion/Introversion and Locus of Control on Satisfaction with Life

\begin{tabular}{|c|c|c|c|c|c|c|c|c|}
\hline Variable & $\mathrm{B}$ & $\begin{array}{c}\mathrm{SE} \\
\mathrm{B})\end{array}$ & $\beta$ & $\mathrm{R}^{2}$ & $\Delta \mathrm{R}^{2}$ & $\mathrm{~F}$ & $\mathrm{t}$ & Tolerance \\
\hline $\mathrm{SL}=\beta_{0}+\beta_{1} \mathrm{EI}(3)$ & .974 & .020 & .974 & .948 & $.948^{*}$ & $2378.844^{*}$ & $48.773^{*}$ & 1.00 \\
\hline $\mathrm{EI}$ & & & \\
\hline $\mathrm{SL}=\beta_{0}+\beta_{1} \mathrm{LOC}(4)$ & -.966 & .023 & -.966 & .834 & $.834^{*}$ & $1839.102^{*}$ & $-42.885^{*}$ & 1.00 \\
\hline
\end{tabular}

The Table 2 shows the results main effects of the regression analysis for the dependent variable, satisfaction with life. It shows that both extraversion/introversion and locus of control are significant predictors of satisfaction with life. The percentage of variance change is $97 \%$ for extraversion/introversion as a determinant of locus of control. Extraversion is positively related to satisfaction with life as per the results $(\beta=$ $.974 ; \mathrm{p}<.05)$. External locus of control has a negative effect on satisfaction with life as the results are significant $(\beta=\quad-.966 ; \mathrm{F}=1839.102 ; \mathrm{p}<0.05)$. Hence hypotheses $\mathrm{H}_{2.1}$ and $\mathrm{H}_{2.2}$ are significant.

\subsection{Mediating Effect}

To predict the mediation effects hypothesized in $\mathrm{H}_{3.1}, \mathrm{H}_{3.2}, \mathrm{H}_{3.3}$ and $\mathrm{H}_{3.4}$ regression analysis is used on the factors obtained for independent variables, dependent variables and the mediator.

To test the mediating effect of online flow experience on the relationship between personality variables and subjective happiness, the following regression equations are employed:

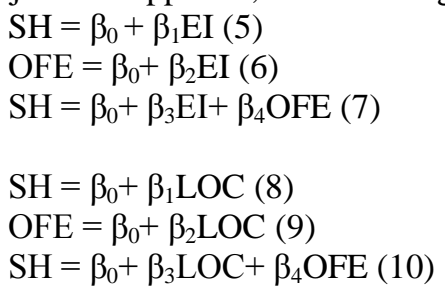

Where, $\quad \beta=$ Regression Coefficient, $\mathrm{SH}=$ Subjective Happiness, EI $=$ Extraversion/ Introversion, LOC $=$ Locus of Control, OFE = Online Flow Experience

Table 3 Summary of Regression Analysis of Role Ambiguity, Role Conflict and Creativity on Job Satisfaction

\begin{tabular}{|c|c|c|c|c|c|c|c|c|}
\hline Variables & $\mathrm{B}$ & SE (B) & $\beta$ & $\mathrm{R}^{2}$ & $\Delta \mathrm{R}^{2}$ & $\mathrm{~F}$ & $\mathrm{t}$ & Tolerance \\
\hline \multicolumn{9}{|c|}{ Subjective Happiness } \\
\hline \multicolumn{9}{|c|}{$\mathrm{SH}=\beta_{0}+\beta_{1} \mathrm{EI}(5)$} \\
\hline EI & .968 & .033 & .968 & .934 & $.934 *$ & $1673.074 *$ & $47.912^{*}$ & 1.00 \\
\hline \multicolumn{9}{|c|}{$\mathrm{OFE}=\beta_{0}+\beta_{2} \mathrm{EI}(6)$} \\
\hline EI & -.965 & .023 & -.965 & .931 & $.931 *$ & 1757.894* & $-41.927 *$ & 1.00 \\
\hline \multicolumn{9}{|c|}{$\mathrm{SH}=\beta_{0}+\beta_{3} \mathrm{EI}+\beta_{4} \mathrm{OFE}(7)$} \\
\hline EI & .969 & .122 & .969 & \multirow[t]{2}{*}{.967} & \multirow[t]{2}{*}{$.967 *$} & \multirow[t]{2}{*}{$1722.286^{*}$} & $48.494^{*}$ & 1.00 \\
\hline OFE & -.391 & .122 & -.391 & & & & $-3.197 *$ & 1.00 \\
\hline \multicolumn{9}{|c|}{ Subjective Happiness } \\
\hline \multicolumn{9}{|c|}{$\mathrm{SH}=\beta_{0}+\beta_{1} \mathrm{LOC}(8)$} \\
\hline LOC & -.834 & .031 & -.834 & .873 & $.873 *$ & $1992.969 *$ & $-29.883 *$ & 1.00 \\
\hline \multicolumn{9}{|c|}{$\mathrm{OFE}=\beta_{0}+\beta_{2} \mathrm{LOC}(9)$} \\
\hline LOC & .955 & .026 & .955 & .912 & $.912 *$ & $1349.227 *$ & $36.732 *$ & 1.00 \\
\hline \multicolumn{9}{|c|}{$\mathrm{SH}=\beta_{0}+\beta_{3} \mathrm{LOC}+\beta_{4} \mathrm{OFE}(10)$} \\
\hline LOC & -.631 & .102 & -.631 & \multirow[t]{2}{*}{.882} & \multirow[t]{2}{*}{$.882 *$} & \multirow[t]{2}{*}{$1481.040^{*}$} & $-16.181 *$ & 1.00 \\
\hline $\mathrm{OFE}$ & .317 & .102 & .317 & & & & $13.107 *$ & 1.00 \\
\hline
\end{tabular}

The regression analysis is used for testing the mediating effects of online flow experiences on the personality variables and subjective happiness. The results of regression analysis are shown in Table 3 . The 
results show that online flow experiences mediated the relationship between personality variables and subjective happiness. The analysis is done in two parts i.e. one for extraversion/introversion and another for locus of control. Results indicated that extraversion/introversion predicted subjective happiness $\{\beta=.868 ; p<0.05 ;(5)\}$ and online flow experience $\{\beta=-.965 ; p<0.05 ;(6)\}$. Extraversion is positively associated with the dependent variable and negatively associated with the online flow experience. Equation (7) for subjective happiness was also significant ( $\mathrm{SH} \beta=.969 ; \mathrm{p}<0.05$ and OFE $\beta=-.391 ; \mathrm{p}<0.05$ ). For extraversion/introversion, $\mathrm{R}^{2}=.967$ of equation (7) is greater than $\mathrm{R}^{2}=.934$ of equation (5). It shows that online flow experience has mediation effect on the relationship between independent variables and dependent variables. It can increase the impact of extraversion on subjective happiness. Hence, online flow experience significantly mediated the relationship between extraversion /introversion and subjective happiness. Similarly locus of control predicted subjective happiness $\{\beta=-.834 ; \mathrm{p}<0.05 ;(8)\}$ and online flow experience $\{\beta=.955 ; \mathrm{p}<0.05 ;(9)\}$. Equation (10) for satisfaction with life was also significant (LOC $\beta=-.631 ; p<0.05$ and OFE $\beta=.317 ; p<0.05$ ) and $R^{2}=.882$ of equation (10) is higher than the $\mathrm{R}^{2}=.873$ of equation (8). It can reduce the negative impact of external locus of control on subjective happiness. Hence, online flow experience significantly mediated the relationship between locus of control and satisfaction with life.

To test the mediating effect of online flow experience on the relationship between personality variables and satisfaction with life, the following regression equations are employed

$$
\begin{aligned}
& \mathrm{SL}=\beta_{0}+\beta_{1} \text { EI }(11) \\
& \mathrm{OFE}=\beta_{0}+\beta_{2} \text { EI (12) } \\
& \mathrm{SL}=\beta_{0}+\beta_{3} \text { EI }+\beta_{4} \text { OFE (13) } \\
& \mathrm{SL}=\beta_{0}+\beta_{1} \text { LOC }(14) \\
& \mathrm{OFE}=\beta_{0}+\beta_{2} \text { LOC }(15) \\
& \mathrm{SL}=\beta_{0}+\beta_{3} \text { LOC }+\beta_{4} \text { OFE (16) }
\end{aligned}
$$

\begin{tabular}{|c|c|c|c|c|c|c|c|c|}
\hline Variables & $\mathrm{B}$ & SE (B) & $\beta$ & $\mathrm{R}^{2}$ & $\Delta \mathrm{R}^{2}$ & $\mathrm{~F}$ & $\mathrm{t}$ & Tolerance \\
\hline \multicolumn{9}{|c|}{ Satisfaction with Life } \\
\hline \multicolumn{9}{|c|}{$\mathrm{SL}=\beta_{0}+\beta_{1} \mathrm{EI}(11)$} \\
\hline EI & .976 & .031 & .976 & .977 & $.977 *$ & $2923.686^{*}$ & $50.392 *$ & 1.00 \\
\hline \multicolumn{9}{|c|}{$\mathrm{OFE}=\beta_{0}+\beta_{2} \mathrm{EI}(12)$} \\
\hline EI & -.965 & .023 & -.965 & .931 & $.931 *$ & $1757.894 *$ & $-41.927 *$ & 1.00 \\
\hline \multicolumn{9}{|c|}{$\mathrm{SL}=\beta_{0}+\beta_{3} \mathrm{EI}+\beta_{4}$ OFE (13) } \\
\hline EI & .988 & .114 & .988 & \multirow[t]{2}{*}{.985} & \multirow[t]{2}{*}{$.985^{*}$} & \multirow[t]{2}{*}{$496.803 *$} & $51.257 *$ & 1.00 \\
\hline OFE & -.351 & .114 & -.351 & & & & $-3.083 *$ & 1.00 \\
\hline \multicolumn{9}{|c|}{ Satisfaction with Life } \\
\hline \multicolumn{9}{|c|}{$\mathrm{SL}=\beta_{0}+\beta_{1} \mathrm{LOC}(14)$} \\
\hline LOC & -.934 & .031 & -.934 & .872 & $.872 *$ & $888.056^{*}$ & $-29.800 *$ & 1.00 \\
\hline \multicolumn{9}{|c|}{$\mathrm{OFE}=\beta_{0}+\beta_{2} \mathrm{LOC}(15)$} \\
\hline LOC & .955 & .026 & .955 & .912 & $.912 *$ & $1349.227 *$ & $36.732 *$ & 1.00 \\
\hline \multicolumn{9}{|c|}{$\mathrm{SL}=\beta_{0}+\beta_{3} \mathrm{LOC}+\beta_{4} \mathrm{OFE}(16)$} \\
\hline LOC & -.547 & .100 & -.547 & \multirow[t]{2}{*}{.887} & \multirow[t]{2}{*}{$.887 *$} & \multirow[t]{2}{*}{$505.023^{*}$} & $-5.471 *$ & 1.00 \\
\hline OFE & .405 & .100 & .405 & & & & $4.056^{*}$ & 1.00 \\
\hline
\end{tabular}

Table 4 Summary of Regression Analysis of Extraversion/Introversion, Locus of Control and Online Flow Experience on Satisfaction with Life

This regression analysis examined the mediation effects of online flow experiences on the personality variables and satisfaction with life. The results of regression analysis are given in Table 4. The results show that online flow experience mediated the relationship between personality variables and satisfaction with life. Results indicated that extraversion/ introversion predicted satisfaction with life $\{\beta=.976 ; \mathrm{p}<0.05 ;(11)\}$ and online flow experience $\{\beta=-.965 ; p<0.05 ;(12)\}$. Extraversion has a positive impact on satisfaction with life and a negative impact on online flow experience. Equation (13) for satisfaction with life was also significant (EI $\beta=$ $.988 ; \mathrm{p}<0.05$ and OFE $\beta=-.351 ; \mathrm{p}<0.05)$. For extraversion/ introversion, $\mathrm{R}^{2}=.985$ of equation (13) is greater than $\mathrm{R}^{2}=.977$ of equation (11). It shows that the positive impact of extraversion on satisfaction with life is enhanced by online flow experiences. Hence, online flow experience significantly mediated the relationship between extraversion/introversion and satisfaction with life. Similarly locus of control predicted satisfaction 
with life $\{\beta=-.934 ; p<0.05 ;(14)\}$ and online flow experience $\{\beta=.955 ; \mathrm{p}<0.05 ;(15)\}$. Equation (16) for satisfaction with life was also significant (LOC $\beta=-.547 ; \mathrm{p}<0.05$ and OFE $\beta=.405 ; \mathrm{p}<0.05$ ) and $\mathrm{R}^{2}=.887$ equation (16) is higher than the $R^{2}=.872$ equation (14). It can reduce the negative impact of external locus of control on satisfaction with life. Hence, creativity significantly mediated the relationship between locus of control and organizational commitment.

\section{Conclusion}

The purpose of the study was to explore the mediating effect of online flow experience in the relationship between personality variables, and subjective happiness and satisfaction with life. Behind the excessive use of the Internet by individuals in recent years, their subjective well being is deteriorated. This study has also contributed to the existing body of research in the context of personality variables and positive psychology. So, the purpose of the present research was to examine the effect of extraversion/introversion and locus of control on subjective happiness and satisfaction with life in the real and virtual world. This study provides empirical evidence to show that extraversion and internal locus of control have a positive effect on subjective happiness and satisfaction with life. On the contrary, introversion and external locus of control have a negative effect on subjective happiness and satisfaction with life. In other words, if an individual is an introvert person having external locus of control, he/she is unhappy and dissatisfied with his/her life. The introverts who are submissive and could not communicate with the real world spent more time online browsing their favorite websites. The individuals with external locus of control who always believe in fate, chance and luck involved more in network navigation as they thought that they are incapable of controlling the outcomes. People who felt incompetent in the real world made more online friends. As these individuals browsed the net for longer period of time, they experience flow in the web. This online flow experience escalates their subjective happiness and their satisfaction with life is enhanced as they identify themselves on the net.

\section{References}

[1] Hoffman, D.L., and Novak, T.P., How to Acquire Customers on the Web. Harvard Business Review, May/June, 2000, 179-188.

[2] Eysenck, H.J., and Eysenck, S.B., Manual of the Eysenck Personality Inventory (University of London Press: London, 1964).

[3] Rotter, J. B., Generalized expectancies for internal versus external control of reinforcement. Psychological Monographs, 80, 1966, $1-28$.

[4] Luciana, R.P., One minute more: Adolescent addiction for virtual world. Procedia Social and Behavioral Sciences, 2, 2010, 37063710 .

[5] Diener, E., Suh, E., Lucas, R.E., and Smith, H.L., Subjective well-being: three decades of progress. Psychological Bulletin, 125, 1999, 276-302.

[6] Diener, E., Subjective well-being. Psychological Bulletin, 95, 1984, 542-575.

[7] Argyle, M., and Lu, L., The happiness of extraverts. Personality and Individual Differences, 11, 1990, $1011-1017$.

[8] Hills, P., and Argyle, M., Happiness, introversion-extraversion and happy introverts. Personality and Individual Differences, 30, 2001, 595-608.

[9] Cheng, H., and Furnham, A., Personality, peer relations, and self-confidence as predictors of happiness and loneliness. Journal of Adolescence, 25, 2002, 327-339

[10] Pannells, T. C., and Claxton, A. F., Happiness, Creative Ideation, and Locus of Control. Creativity Research Journal, 20, 2008, 6771.

[11] Diener,E., Oishi, S., and Lucas, R. E., Personality, Culture, and Subjective Well-Being: Emotional and Cognitive Evaluations of Life. The Annual Review of Psychology, 54, 2003, 403-425.

[12] Abu-Bader, S. H., Rogers, A., and Barusch, A. S., Predictors of Life Satisfaction in Frail Elderly. Journal of Gerontological Social Work, 38, 2002, 3-17.

[13] Srivastava, K., Shukla, A., and Sharma, N.K., Online Flow Experiences: The Role of Need for Cognition, Self-Efficacy, and Sensation Seeking Tendency. IJBIT, 3, 2010, 93-100.

[14] Csikszentmihalyi, M., Beyond boredom and anxiety (Jossey-Bass: San Francisco, 1977).

[15] Amichai-Hamburger, Y., Wainapel, G., and Fox, S., On the Internet No One Knows I'm an Introvert": Extroversion, Neuroticism, and Internet Interaction. Cyber Psychology and Behaviour, 5, 2002, 125-128.

[16] Rotsztein, B., Problem Internet use and locus of control among college students: Preliminary findings, Poster session presented at the 35th Annual Conference of the New England Educational Research Organization Portsmouth, New Hampshire, 2003.

[17] Chak, K., and Leung, L., Shyness and locus of control as predictors of internet addiction and internet use. Cyberpsychology \& Behaviour, 7, 2004, 559-570. 